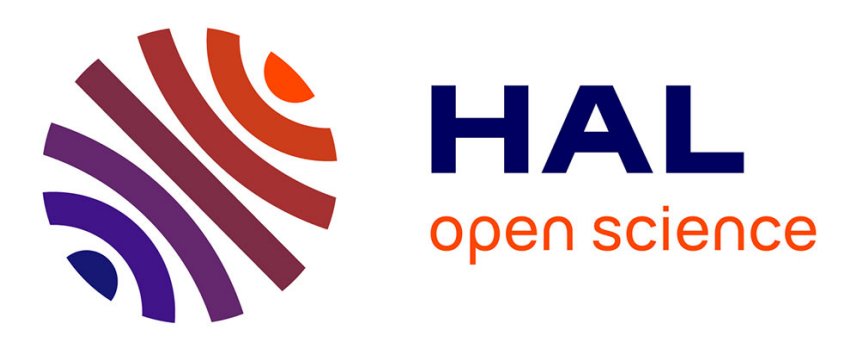

\title{
An LPV Control Approach for Comfort and Suspension Travel Improvements of Semi-Active Suspension Systems
} Anh Lam Do, Cristiano Spelta, Sergio Savaresi, Olivier Sename, Luc Dugard, Diego Delvecchio

\section{- To cite this version:}

Anh Lam Do, Cristiano Spelta, Sergio Savaresi, Olivier Sename, Luc Dugard, et al.. An LPV Control Approach for Comfort and Suspension Travel Improvements of Semi-Active Suspension Systems. CDC 2010 - 49th IEEE Conference on Decision and Control, Dec 2010, Atlanta, Georgie, United States. hal-00533206

\section{HAL Id: hal-00533206 https://hal.science/hal-00533206}

Submitted on 5 Nov 2010

HAL is a multi-disciplinary open access archive for the deposit and dissemination of scientific research documents, whether they are published or not. The documents may come from teaching and research institutions in France or abroad, or from public or private research centers.
L'archive ouverte pluridisciplinaire HAL, est destinée au dépôt et à la diffusion de documents scientifiques de niveau recherche, publiés ou non, émanant des établissements d'enseignement et de recherche français ou étrangers, des laboratoires publics ou privés. 


\title{
An LPV Control Approach for Comfort and Suspension Travel Improvements of Semi-Active Suspension Systems
}

\author{
Anh Lam Do, Cristiano Spelta, Sergio Savaresi, Olivier Sename, Luc Dugard and Diego Delvecchio
}

\begin{abstract}
In this paper, we present a new $H_{\infty} / L P V$ control method to improve the trade-off between comfort and suspension travel. Firstly, a semi-active automotive suspension equipped with a nonlinear static semi-active damper is presented. Secondly, the semi-active suspension system is reformulated in the LPV framework which can be handled in a polytopic way. Finally, in numerical analysis, to emphasize the performance of the proposed controller, the end-stop event is introduced. The results show that the proposed method provides a good improvement in comfort and suspension travel compared with other strategies.
\end{abstract}

\section{INTRODUCTION}

Among the many different types of controlled suspensions (see e.g. [1] for a detailed classification), semi-active suspensions have received a lot of attention in the last two decades, since they provide the best compromise between cost (energy-consumption and actuators/sensors hardware) and performance (see e.g. [2], [3], [4], [5], [6], [7]).

A classical semi-active suspension is characterized by the closed-loop regulation of the damping coefficient; the electronic modulation of the damping coefficient is obtained with Magneto-Rheological (MR), Electro-Rheological (ER) or Electro-Hydraulic (EH) technologies. In the last years, variable-damping semi-active suspensions have had a large growth, and today they are employed over a wide range of application domains: road vehicles suspensions, cabin suspensions in trucks or agricultural tractors, seat suspensions, lateral suspensions in high-speed trains, etc. (see e.g. [6], [8], [9], [10], [11], [12], [13], [14], [7], [15]).

It can be seen that the main semi-active suspension control problems to be solved are trade-offs between comfort, handling and suspension travel. In [16], the semi-active control problem has been explored using Linear Parameter Varying $(L P V)$ technique. The methodology is based on a nonlinear static model of the semi-active damper, where the bi-viscous and hysteretic behaviors of the semi-active damper are taken into account. Then, the nonlinear system associated with the quarter vehicle model is reformulated in the $L P V$ framework. The passivity problem of semi-active dampers is recast into the problem of input saturation. Finally, the $H_{\infty} / L P V$ controller is synthesized to achieve the performance

A. L. Do, O. Sename and L. Dugard are with GIPSA-lab, Control Systems Dept, CNRS-Grenoble INP, ENSE3, BP 46, F-38402 St Martin d'Hères cedex, France $\{a n h-l a m . d o, ~ o l i v i e r . s e n a m e$, luc.dugard\}@gipsa-lab.grenoble-inp.fr

C. Spelta is with Università degli Studi di Bergamo, viale Marconi 5, 24044 Dalmine (BG) - Italy cristiano.spelta@unibg.it

S. Savaresi, D. Delvecchio are with Dipartimento di Elettronica e Informazione, Politecnico di Milano, Piazza L. da Vinci, 32,20133, Milano Italy $\{$ savaresi, delvecchio\}elet.polimi.it objectives (passenger comfort and handling) while satisfying the passivity constraint of semi-active dampers.

In this paper, the trade-off between passenger comfort and suspension travel will be considered. It is quite obvious, while the comfort/handling trade-off has been studied in many approaches during the past decades, that the suspension travel issue has not been always considered. Hitting the structural limits when road disturbance is particularly tough degrades dramatically the passenger comfort (the so-called end-stop effect) and decreases the lifetime of vehicle components. The $L P V$ control method used in [16] is modified by including a comfort oriented control rule - Acceleration Driven Damping Control (ADD) (see e.g [7]) and a scheduling factor that permits an improvement of suspension travel.

The outline is as follows. In Section II, the quarter car model with a nonlinear semi-active damper and the control problem on this model are presented. In Section III, a new $H_{\infty} / L P V$ controller to improve the trade-off between comfort and suspension travel is designed. In Section IV, the results obtained in simulations with a nonlinear quarter car model are discussed. Finally, some conclusions and perspectives are drawn in Section V.

\section{Problem Statement}

\section{A. Quarter Car Model}

Consider a simple model of quarter vehicle (see Fig. 1) made up of a sprung mass $\left(m_{s}\right)$ and an unsprung mass $\left(m_{u s}\right)$. A spring with the stiffness coefficient $k_{s}$ and a semi-active damper connect both masses. The wheel tire is modeled by a spring with the stiffness coefficient $k_{t}$. In this model, $z_{s}$ (respectively $z_{u s}$ ) is the vertical position of $m_{s}$ (respectively $\left.m_{u s}\right)$ and $z_{r}$ is the road profile. It is assumed that the wheelroad contact is ensured.

The dynamical equations of a quarter vehicle are governed

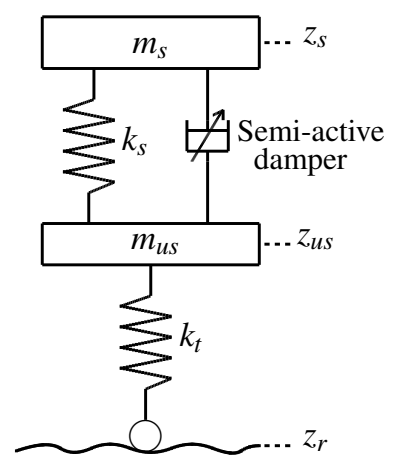

Fig. 1. Model of quarter vehicle with a semi-active damper. 
by

$$
\left\{\begin{array}{l}
m_{s} \ddot{z}_{s}=-F_{\text {spring }}-F_{\text {damper }} \\
m_{u s} \ddot{z}_{u s}=F_{\text {spring }}+F_{\text {damper }}-k_{t}\left(z_{u s}-z_{r}\right)
\end{array}\right.
$$

where $F_{\text {spring }}=k_{s} z_{\text {def }}$ is the spring force, $z_{\text {def }}=z_{s}-z_{u s}$ is the damper deflection (assumed to be measured or estimated), $\dot{z}_{\text {def }}=\dot{z}_{s}-\dot{z}_{u s}$ is the deflection velocity.

In this paper, the behavior of a realistic semi-active suspension is represented using the following nonlinear equation, as in [17]

$$
F_{\text {damper }}=c_{0} \dot{z}_{\text {def }}+k_{0} z_{\text {def }}+f_{I} \tanh \left(c_{1} \dot{z}_{\text {def }}+k_{1} z_{\text {def }}\right)
$$

where $c_{0}, k_{0}, c_{1}$ and $k_{1}$ are constant parameters and $f_{I}$ is a controllable force. The interest in this model is that it allows fulfilling the passivity constraint of the semi-active damper by considering only the constraint

$$
0 \leq f_{\min } \leq f_{I} \leq f_{\max }
$$

The dynamical equations (1)-(2) can then be rewritten as

$$
\left\{\begin{array}{c}
m_{s} \ddot{z}_{s}=-\left(k_{s}+k_{0}\right) z_{d e f}-c_{0} \dot{z}_{d e f}-f_{I} \tanh \left(c_{1} \dot{z}_{d e f}+k_{1} z_{d e f}\right) \\
m_{u s} \ddot{z}_{u s}=\left(k_{s}+k_{0}\right) z_{d e f}+c_{0} \dot{z}_{d e f}+f_{I} \tanh \left(c_{1} \dot{z}_{d e f}+k_{1} z_{d e f}\right) \\
-k_{t}\left(z_{u s}-z_{r}\right)
\end{array}\right.
$$

\section{B. The End-stop Phenomenon}

The end-stop phenomenon happens when the piston hits the rubber bushings because of the tough road disturbance. This phenomenon generates a shock that makes passengers uncomfortable. In this paper, the end-stop effect is simply modeled as follows:

$$
F_{\text {spring }}=\left\{\begin{array}{lll}
k_{s} z_{\text {def }} & \text { if } & \left|z_{\text {def }}\right|<\Delta_{e s} \\
k_{\text {es }} z_{\text {def }} & \text { if } & \left|z_{\text {def }}\right| \geq \Delta_{e s}
\end{array}\right.
$$

where $\Delta_{e s}$ is the suspension stroke and $k_{e s} \gg k_{s}$ (typically represents the stiffness of rubber bushings).

The end-stop effect is shown in Fig. 2. It is obvious that hitting the structural limits deteriorates dramatically the car body acceleration (i.e the passenger comfort).
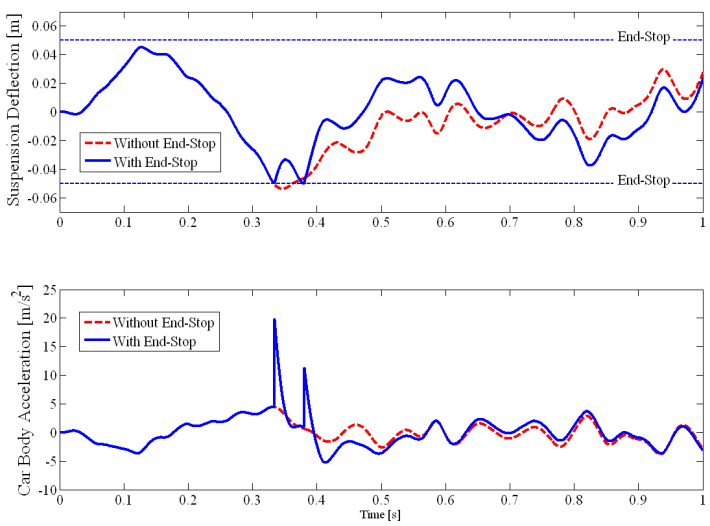

Fig. 2. Time history of the suspension deflection (top) and the body acceleration (bottom), with and without the end-stops.

\section{Cost Function}

In this paper, the following criteria are used to evaluate the performance of the proposed controller

$$
\begin{gathered}
J_{a c c}=\sqrt{\frac{1}{T} \int_{0}^{T} \ddot{\bar{z}}_{s}^{2}(t)} \\
J_{d e f}=\sqrt{\frac{1}{T} \int_{0}^{T} z_{d e f}^{2}(t)}
\end{gathered}
$$

where $\ddot{\bar{z}}_{S}(t)$ is the filtered car body acceleration (by ISO 2631 filter) $\left[\mathrm{m} / \mathrm{s}^{2}\right], z_{\text {def }}$ is the damper deflection $[\mathrm{m}]$ and $T$ is the simulation running time $[s]$. The ISO 2631 filter (see [18]) represents the sensitivity of human to body car acceleration and is given as

$$
F_{I S O-2631}=\frac{81.89 s^{3}+796.6 s^{2}+1937 s+0.1446}{s^{4}+80.00 s^{3}+2264 s^{2}+7172 s+21196}
$$

The criteria (6) and (7) are used to evaluate the comfort and the suspension travel, respectively. It can be seen that when the end-stop event occurs, the peak values in car body acceleration (as seen in Fig. 2) resulting from this effect will be taken into account in $J$.

\section{Acceleration Driven Damping Control (ADD)}

This paper is based on the extension of $A D D$ control rule [6]. The $A D D$ is based on a linear model of the electronic shock absorber, $F=c \dot{z}_{\text {def }}$ where $\dot{z}_{\text {def }}$ is the suspension deflection velocity and $c$ is the damping coefficient that may vary from a minimum value $c_{\min }$ to a maximum value $c_{\max }$.

The $A D D$ switching rule is as follows:

$$
c= \begin{cases}c_{\text {max }} & \text { if } \ddot{z}_{s} \dot{z}_{\text {def }}>0 \\ c_{\text {min }} & \text { if } \ddot{z}_{s} \dot{z}_{\text {def }} \leq 0\end{cases}
$$

$A D D$, a comfort-oriented control method, has been proven to approximate the solution of an optimal control problem where the cost function is the integral of the squared body car acceleration, the suspension system is modeled as a linear quarter car, the road disturbance is described as a white noise and the optimization horizon is based on one step of simulation. The limitation of this method is that the suspension travel has been not improved.

\section{Control Design For Comfort And Stroke}

To obtain a better compromise between the ride quality and the suspension travel, a new control method is presented as follows

$$
\begin{aligned}
f_{I} & =f_{\text {max }} h_{s w}+\left(u+\alpha f_{\max }\right)\left(1-h_{s w}\right) \\
& =f_{\max }\left[\alpha+h_{s w}(1-\alpha)\right]+u\left(1-h_{s w}\right)
\end{aligned}
$$

where $0 \leq \alpha \leq 1$ and $h_{s w} \in\{0,1\}$ are two parameters and $u$ is the control input to design. In the following, the roles of $\alpha, h_{s w}$ and $u$ are explained.

- The switching control rule $h_{s w}$ is chosen so that it specially enhances the passenger comfort. In this paper, the design of $h_{s w}$ is based on the $A D D$ control rule (9). 
- It can be seen that the smaller $\alpha$, the more comfortable the car but the bigger the suspension travel and viceversa.

- The control input $u$ is designed in the $H_{\infty} / L P V$ framework to improve the suspension travel without deteriorating the comfort too much for all values of $h_{s w}$ and $\alpha$.

\section{A. Design of Comfort-Oriented Switching Controller $h_{s w}$}

The following control rule is inspired by the existing ADD algorithm developed for the linear suspension systems in [7]. The idea turns out to be very simple. Looking at (1) and (2), the only variable parameter is $f_{I}$, so when $\ddot{z}_{s} \tanh \left(c_{1} \dot{z}_{\text {def }}+k_{1} z_{\text {def }}\right)>0$, for example $\ddot{z}_{s}$ and $\tanh \left(c_{1} \dot{z}_{d e f}+k_{1} z_{d e f}\right)$ are positive, $\ddot{z}_{s}$ will rapidly decrease to zero if $f_{I}=f_{\max }$. On the contrary, when $\ddot{z}_{s} \tanh \left(c_{1} \dot{z}_{\text {def }}+k_{1} z_{\text {def }}\right) \leq 0, \ddot{z}_{s}$ will be kept not floating away from zero if $f_{I}=f_{\min }$. Hence, the on-off comfort-oriented control rule is summarized as follows:

$$
f_{I}=\left\{\begin{array}{rr}
f_{\text {max }} & \text { if } \left.\ddot{z}_{s} \tanh \left(c_{1} \dot{z}_{\text {def }}+k_{1} z_{\text {def }}\right)>0\right) \\
& \left(\text { i.e } h_{s w}=1\right) \\
f_{\min } & \text { if } \left.\ddot{z}_{s} \tanh \left(c_{1} \dot{z}_{\text {def }}+k_{1} z_{\text {def }}\right) \leq 0\right) \\
& \left(\text { i.e } h_{s w}=0\right)
\end{array}\right.
$$

Noticing that in the case of linear semi-active damper, $k_{1}=0$, $\operatorname{sign}\left(\tanh \left(c_{1} \dot{z}_{\text {def }}+k_{1} z_{\text {def }}\right)\right) \equiv \operatorname{sign}\left(\dot{z}_{\text {def }}\right)$, the rule (11) is the same as the conventional ADD algorithm.

\section{B. Choice of $\alpha$}

In order to detect the suspension travel limits (the Endstop event) and to enlarge as much as possible the capacity of the $H_{\infty} / L P V$ controllers, $\alpha$ can be chosen as

$$
\alpha(\varepsilon)=0.5 \frac{\mu \varepsilon^{2 n}}{\mu \varepsilon^{2 n}+1 / \mu}
$$

where $\mu$ modifies the slope of the $\alpha(\varepsilon)$ function and is chosen sufficiently high, $n$ is an integer. See Fig. 3 for various values of $\alpha$.

In this paper, $\varepsilon=z_{\text {def }}+\dot{z}_{\text {def }} / \lambda$. The factor $\lambda$ can be roughly chosen so that $\alpha(\varepsilon)$ is close to zero when the car body acceleration of the open loop system $\left(f_{I}=0\right)$ is close to zero. Not that, from Eq. (4), one has

$$
\ddot{z}_{s}=0 \Leftrightarrow z_{\text {def }}+\frac{c_{0}}{k_{s}+k_{0}} \dot{z}_{\text {def }}=0 \quad\left(\text { with } f_{I}=0\right)
$$

So $\lambda=\left(k_{s}+k_{0}\right) / c_{0}$ can be a good choice.

\section{C. $H_{\infty} / L P V$ Control Design u}

From Eq. (10), the constraint (3) on $f_{I}$ is tantamount to the following inequality

$$
|u| \leq f_{\alpha}
$$

where $f_{\alpha}=\min \{\alpha, 1-\alpha\} f_{\max }$. Hence, the passivity constraint of the semi-active damper is recast as the saturation constraint on the control input $u$.

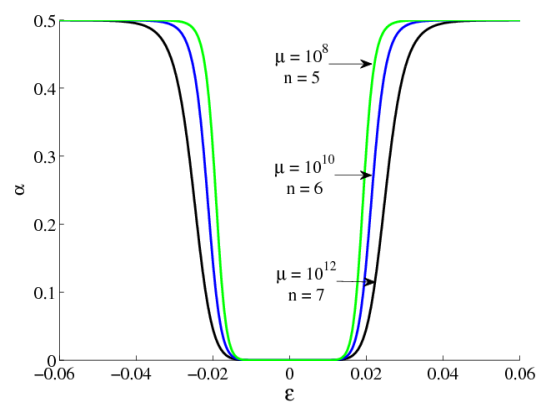

Fig. 3. Various values of $\alpha$

1) LPV Formulation For Ideal Linear Design: For simplicity, in this step, the saturation constraint (13) is omitted. The nonlinear model (1)-(2)-(10) is now rewritten in the LPV framework.

$$
P:\left\{\begin{array}{c}
\dot{x}_{s}=\left(A_{s}+B_{s 2} \frac{\left[\alpha+h_{s w}(1-\alpha)\right] \tanh \left(C_{s 2} x_{s}\right)}{C_{s 2} x_{s}} C_{s 2}\right) x_{s} \\
\quad+B_{s}\left(1-h_{s w}\right) \tanh \left(C_{s 2} x_{s}\right) u+B_{s 1} w \\
y=C_{s} x_{s}
\end{array}\right.
$$

where $x_{s}=\left(z_{s}, \dot{z}_{s}, z_{u s}, \dot{z}_{u s}\right)^{T}, u$ : control input, $w=z_{r}$ disturbance, $y=z_{s}-z_{u s}$ measurement output,

$$
\begin{aligned}
& A_{s}=\left(\begin{array}{cccc}
0 & 1 & 0 & 0 \\
-\frac{k_{s}+k_{0}}{m_{s}} & -\frac{c_{0}}{m_{s}} & \frac{k_{s}+k_{0}}{m_{s}} & \frac{c_{0}}{m_{s}} \\
0 & 0 & 0 & 1 \\
\frac{k_{s}+k_{0}}{m_{u s}} & \frac{c_{0}}{m_{u s}} & -\frac{k_{s}+k_{0}+k_{t}}{m_{u s}} & -\frac{c_{0}}{m_{u s}}
\end{array}\right) \\
& B_{s}=\left(\begin{array}{c}
0 \\
-\frac{1}{m_{s}} \\
0 \\
\frac{1}{m_{u s}}
\end{array}\right), B_{s 1}=\left(\begin{array}{c}
0 \\
0 \\
0 \\
\frac{k_{t}}{m_{u s}}
\end{array}\right), B_{s 2}=\left(\begin{array}{c}
0 \\
-\frac{f_{\max }}{m_{s}} \\
0 \\
\frac{f_{\max }}{m_{u s}}
\end{array}\right) \text {, } \\
& C_{s}=(1,0,-1,0), C_{s 2}=\left(k_{1}, c_{1},-k_{1},-c_{1}\right)
\end{aligned}
$$

In (14) the control input matrix $B_{s}\left(1-h_{s w}\right) \tanh \left(C_{s 2} x_{s}\right)$ is parameter dependent, which is not consistent with the solution of the $H_{\infty}$ design problem for systems as in [19], [20]. This problem can be easily solved by adding a strictly proper filter into (14) to make the controlled input matrix independent from the scheduling parameter (see [21]). Besides, this filter allows for modeling low-pass dynamics of semi-active dampers.

$$
F:\left(\begin{array}{c}
\dot{x}_{f} \\
u
\end{array}\right)=\left(\begin{array}{cc}
A_{f} & B_{f} \\
C_{f} & 0
\end{array}\right)\left(\begin{array}{c}
x_{f} \\
u_{c}
\end{array}\right)
$$

where $A_{f}, B_{f}, C_{f}$ are constant matrices and $u_{c}$ is the controller output.

2) LPV Reformulation For Linear Design with Input Saturation: Let now include the saturation constraint (13) in the LPV controller design. First the system is augmented by adding a saturating function block as in Fig. 4. where

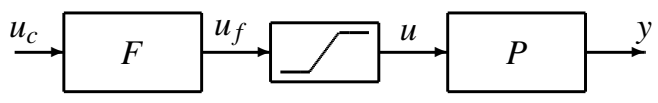

Fig. 4. Linear design with input saturation. 


$$
u=\operatorname{sat}\left(u_{f}\right)=\left\{\begin{array}{ccc}
f_{\alpha} & \text { if } & u_{f}>f_{\alpha} \\
u_{f} & \text { if } & -f_{\alpha} \leq u_{f} \leq f_{\alpha} \\
-f_{\alpha} & \text { if } & u_{f}<-f_{\alpha}
\end{array}\right.
$$

To cope with a linear control design, the saturation function $\operatorname{sat}\left(u_{f}\right)$ is roughly approximated by a tangent hyperbolic function: $f_{\alpha} \tanh \left(\frac{u_{f}}{f_{\alpha}}\right)$ or $f_{\alpha} \tanh \left(\frac{C_{f} x_{f}}{f_{\alpha}}\right)$. The interest of the use of tangent hyperbolic function is its bounded derivative which may be exploited in LPV design with parametersdependent Lyapunov function to reduce the conservatism (in future work). The state-space representation of the transfer function from $u_{c}$ to $u$ is then:

$$
F_{1}:\left(\begin{array}{c}
\dot{x}_{f} \\
u
\end{array}\right)=\left(\begin{array}{cc}
A_{f} & B_{f} \\
C_{f} \tanh (\psi) / \psi & 0
\end{array}\right)\left(\begin{array}{c}
x_{f} \\
u_{c}
\end{array}\right)
$$

where $\psi=\frac{C_{f} x_{f}}{f_{\alpha}}$

Finally, from (14) and (17), an LPV model formulation for the semi-active suspension control problem is given as follows

$$
\left\{\begin{array}{l}
\dot{x}=A\left(\rho_{1}, \rho_{2}\right) x+B u_{c}+B_{1} w \\
y=C x
\end{array}\right.
$$

where $x=\left(\begin{array}{ll}x_{s}{ }^{T} & x_{f}{ }^{T}\end{array}\right)^{T}$

$$
\begin{aligned}
& A\left(\rho_{1}, \rho_{2}\right)=\left(\begin{array}{cc}
A_{s}+\rho_{2} B_{s 2} C_{s 2} & \rho_{1} B_{s} C_{f} \\
0 & A_{f}
\end{array}\right), \\
& B=\left(\begin{array}{c}
0 \\
B_{f}
\end{array}\right), B_{1}=\left(\begin{array}{c}
B_{s 1} \\
0
\end{array}\right), C=\left(\begin{array}{c}
C_{s} \\
0
\end{array}\right)^{T}
\end{aligned}
$$

and two scheduling parameters

$$
\rho_{1}=\left(1-h_{s w}\right) \tanh \left(C_{s 2} x_{s}\right) \frac{\tanh (\psi)}{\psi} \text { where } \psi=\frac{C_{f} x_{f}}{f_{\alpha}}
$$$$
\rho_{2}=\left[\alpha+h_{s w}(1-\alpha)\right] \frac{\tanh \left(C_{s 2} x_{s}\right)}{C_{s 2} x_{s}}
$$

Let us note that the LPV formulation presented above is similar to the one given in [16]. The main difference relies on both scheduling parameters $\rho_{1}$ and $\rho_{2}$ which here depend on the exogenous signals $h_{s w}$ and $\alpha$. This will be useful to improve of comfort and suspension travel, respectively, while the same is not true in the LPV formulation in [16].

Note also that $\rho_{1}$ and $\rho_{2}$ are not independent. Fig. 5 depicts the set of $\left(\rho_{1}, \rho_{2}\right)$. It is represented by the bounded area below the continuous curve.

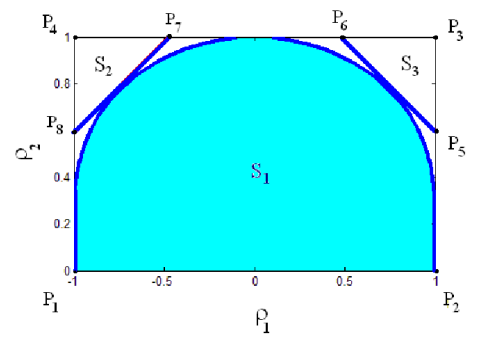

Fig. 5. Scheduling parameters $\rho_{1}$ and $\rho_{2}$
3) Comfort/Stroke $H_{\infty} / L P V$ Controller: The structure for the controller synthesis is presented in Fig. 6 . The $H_{\infty}$ control problem for the LVP system (with scheduling parameters $\rho_{1}$ and $\left.\rho_{2}\right)$ consists in finding an LPV controller $K\left(\rho_{1}, \rho_{2}\right)$ such that the closed-loop system is quadratically stable and that, for a given positive real $\gamma$, the $L_{2}$-induced norm of the operator mapping $w_{1}$ into $\left(z_{1}, z_{2}\right)^{T}$ is bounded by $\gamma$ for all possible trajectories of $\left(\rho_{1}, \rho_{2}\right)^{T}$. The $H_{\infty} / L P V$ controller can be obtained by solving an LMIs problem (see [19] and [20]).

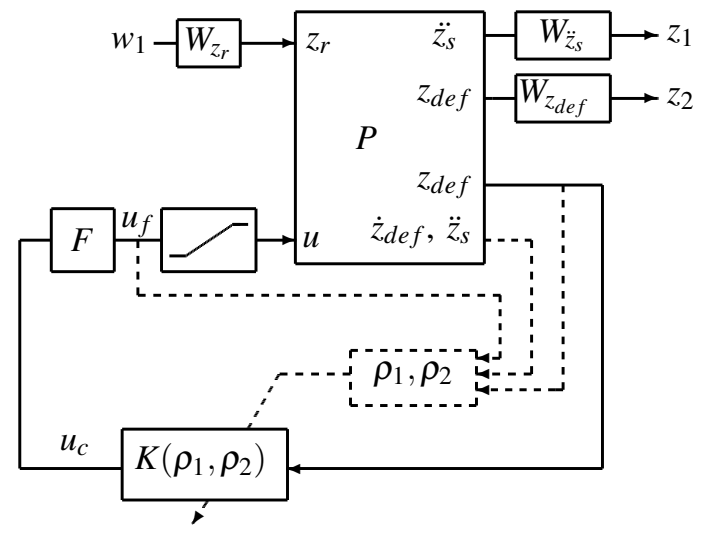

Fig. 6. Structure for $H_{\infty} / L P V$ controller design.

Although they are not independent, $\rho_{1}$ and $\rho_{2}$ are considered in this design as independent parameters and $\left(\rho_{1}, \rho_{2}\right)$ belongs to a larger polytope whose vertices are $P_{1}=(-1,1)$, $P_{2}=(1,0), P_{3}=(1,1), P_{4}=(0,1)$. At each vertex, a local $H_{\infty}$ controller will be found. Then, a convex hull of these local controllers gives the global LPV controller.

As seen in Eq. (12) and Eq. (13), the role of $u$ is strongly emphasized when $\alpha \approx 0.5$ (i.e when the suspension is going to reach its structural limits). The aim of the $H_{\infty} / L P V$ design is to minimize the frequency response $z_{\text {def }} / z_{r}$ in high frequencies [5-20] $\mathrm{Hz}$ (the suspension deflection is normally large around the "tyrehop frequency" $\sqrt{k_{t} / m_{u s}} \approx 12 \mathrm{~Hz}$ ) while not deteriorating much $\ddot{z}_{s} / z_{r}$. Therefore the weighting functions for the $H_{\infty}$ controller synthesis have been chosen as:

$$
W_{\ddot{z} s}=3.65 \frac{s^{2}+2 \xi_{11} \Omega_{1} s+\Omega_{1}^{2}}{s^{2}+2 \xi_{12} \Omega_{1} s+\Omega_{1}{ }^{2}}
$$

where $\Omega_{1}=2 \pi f_{1}$ with $f_{1}=10.7685 \mathrm{~Hz}, \xi_{11}=5.65, \xi_{12}=$ 0.091 , and

$$
W_{z_{\text {def }}}=0.0218 \frac{s^{2}+2 \xi_{21} \Omega_{1} s+\Omega_{2}^{2}}{s^{2}+2 \xi_{22} \Omega_{1} s+\Omega_{2}^{2}}
$$

where $\Omega_{2}=2 \pi f_{2}$ with $f_{2}=10.3 \mathrm{~Hz}, \xi_{21}=4.71, \xi_{22}=$ 2.2326 .

\section{Analysis on Fixed Values of $\alpha$}

The following frequency response analysis is done by using the "variance gain" algorithm (see [6]) for nonlinear systems. The "variance gain" is simple and provides a good approximation to frequency response. In Fig. 7 and Fig. 8, 
the frequency responses of the closed-loop systems are done with $\alpha=0$ (good for comfort) and $\alpha=0.5$ (good for stroke). These responses are upper and lower bounds of the closedloop systems. All intermediate frequency responses of the closed-loop systems, $0 \leq \alpha \leq 0.5$, will be found between these two bounds.

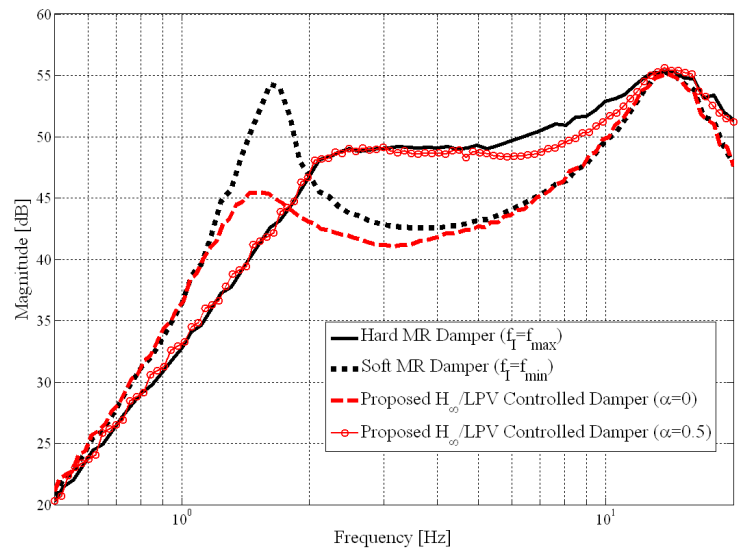

Fig. 7. Frequency responses $\ddot{z}_{s} / z_{r}$

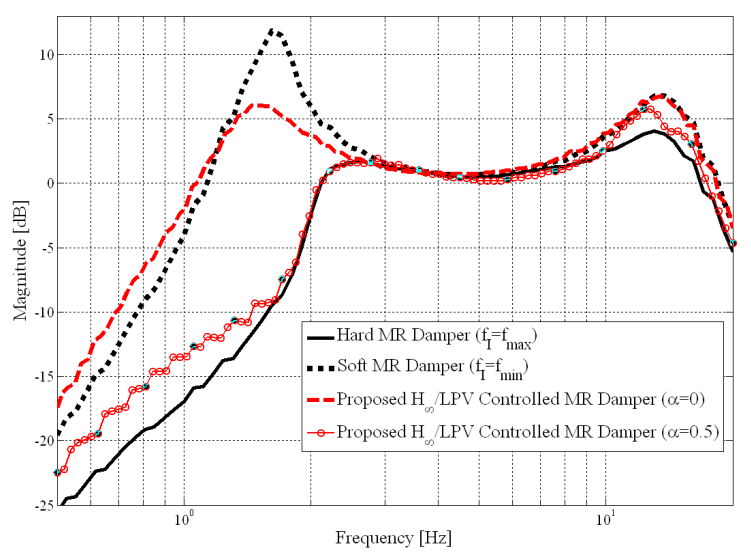

Fig. 8. Frequency responses $z_{d e f} / z_{r}$

\section{Numerical Results}

The quarter vehicle used in this paper is the quarter car Renault Mégane Coupé (1/4 RMC) model (see [22]) with the parameters presented in Tab. I. The spring used in this simulation has a nonlinear characteristics. The MR damper model parameters are chosen according to the MR damper in [23] and summarized in Tab. I. In this numerical analysis, $\alpha$ is chosen as in Eq. (12) with $\mu=10^{8}, n=5$ and $\lambda=30$.

The standard road profile is represented by an integrated white noise, band-limited within the frequency range [030] $\mathrm{Hz}$ (see Fig. 9). The performance index (6) and (7) will be calculated with different road-profiles obtained by multiplying the standard road-profile by a scaling factor $\beta$. To check the constraints of the $H_{\infty} / L P V$ control design, a road profile with $\beta=2$ is chosen as the input disturbance. Looking at Fig. 10, the results show that the passivity

\begin{tabular}{llll} 
1/4 RMC & Value & MR damper & Value \\
\hline$m_{s}$ & $315[\mathrm{~kg}]$ & $c_{0}$ & $810.78[\mathrm{Ns} / \mathrm{m}]$ \\
$m_{u s}$ & $37.5[\mathrm{~kg}]$ & $k_{0}$ & $620.79[\mathrm{~N} / \mathrm{m}]$ \\
$k_{s}$ & $29500[\mathrm{~N} / \mathrm{m}]$ & $f_{\min }$ & $0[\mathrm{~N}]$ \\
$k_{t}$ & $210000[\mathrm{~N} / \mathrm{m}]$ & $f_{\max }$ & $914[\mathrm{~N}]$ \\
- & - & $c_{1}$ & $13.76[\mathrm{~s} / \mathrm{m}]$ \\
- & - & $k_{1}$ & $10.54[1 / \mathrm{s}]$ \\
- & - & $\Delta_{e s}$ & $0.05[\mathrm{~m}]$ \\
\hline
\end{tabular}

TABLE I

PARAMETER VALUES.

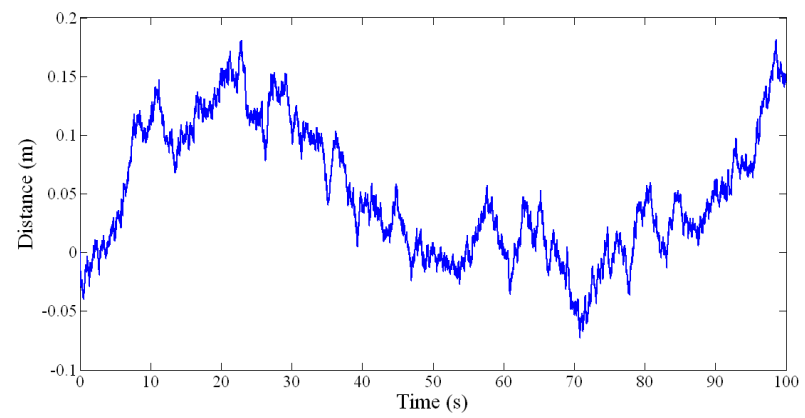

Fig. 9. Standard road profile $z_{r}$

constraint is satisfied since the controllable force $f_{I}$ is kept in the range $[0-900] N$ because $|u| \leq f_{\alpha}$ where $\max \left(f_{\alpha}\right)=450$ $[\mathrm{N}]$.

The comparisons of the performance for different strategies, with $\beta$ in $[0.5-3]$, are presented in Fig. 11-12-13. In general, the semi-active suspension with the proposed $H_{\infty} / L P V$ control method is less sensitive to road input disturbances and provides a better comfort than other strategies. It then achieves the best compromise between comfort and suspension travel.

\section{COnClusions}

In this paper, an $H_{\infty} / L P V$ controller is designed to improve the compromise between the passenger comfort and the suspension travel. The simulation results have shown that the proposed control strategy provides a good passenger comfort and a good suspension travel while the passivity constraint is always satisfied.

The next step is to reduce the conservatism in the controller design. To do that, the smaller polytope $P_{1} P_{2} P_{5} P_{6} P_{7} P_{8}$ can be employed instead of the one used in this paper $P_{1} P_{2} P_{3} P_{4}$, as seen in Fig. 5. In addition, by analogy, the tradeoff between comfort and road holding will be considered in future works.

\section{REFERENCES}

[1] R. Isermann, Mechatronic Systems: Fundamentals. Springer Verlag, 2003.

[2] I. Fialho and G. Balas, "Road adaptive active suspension design using linear parameter varying gain scheduling," IEEE Transaction on Control System Technology, vol. 10, no. 1, pp. 43-54, january 2002.

[3] T. D. Gillespie, Fundamentals of Vehicle Dynamics. Society of Automotive Engineers Inc, 1992.

[4] D. Hrovat, "Survey of advanced suspension developments and related optimal control application," Automatica, vol. 33, no. 10, pp. 17811817, october 1997. 

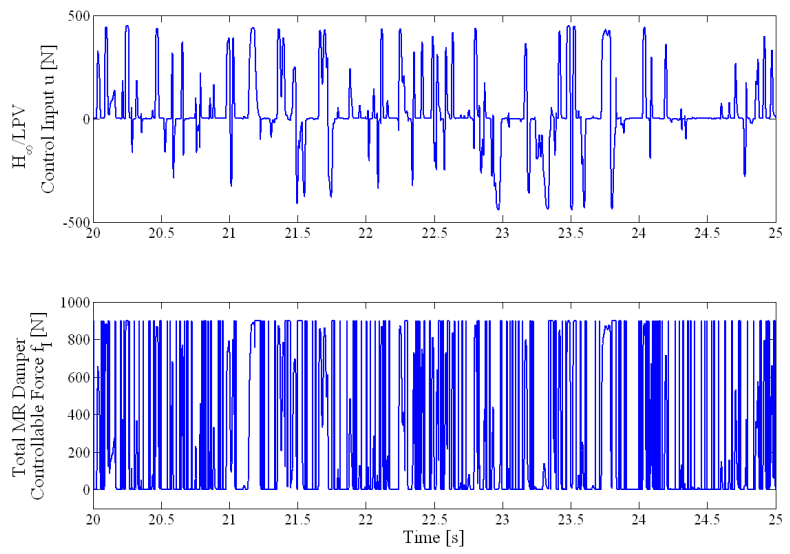

Fig. 10. Controllable forces

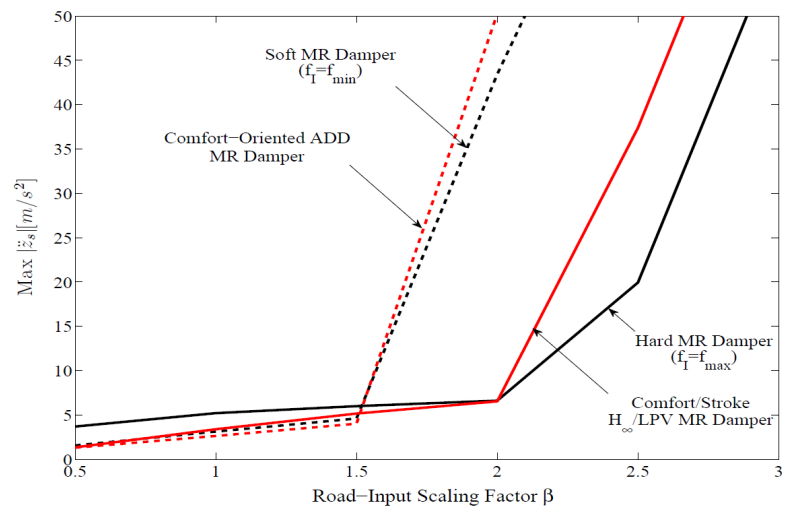

Fig. 11. Performance comparison: Peak value of acceleration

[5] U. Kiencke and L. Nielsen, Automotive Control Systems for Engine, Driveline, and Vehicle. Springer Verlag, 2000.

[6] S. Savaresi and C. Spelta, "Mixed sky-hook and ADD: Approaching the filtering limits of a semi-active suspension," ASME Transactions: Journal of Dynamic Systems, Measurement and Control, vol. 129, no. 4, pp. 382-392, 2007.

[7] S. Savaresi, E. Silani, and S. Bittanti, "Acceleration driven damper (ADD): an optimal control algorithm for comfort oriented semiactive suspensions," ASME Transactions: Journal of Dynamic Systems, Measurements and Control, vol. 127, no. 2, pp. 218-229, 2005.

[8] M. Ahmadian, B. A. Reichert, and X. Song, "System nonlinearities induced by skyhook dampers," Shock and Vibration, vol. 8, no. 2, pp. 95-104, 2001.

[9] S. B. Choi, J. H. Choi, Y. S. Lee, and M. S. Han, "Vibration control of an er seat suspension for a commercial vehicle," ASME Journal of Dynamic Systems, Measurement and Control, vol. 125, no. 1, pp. 60-68, 2003.

[10] K. J. Kitching, D. J. Cole, and D. Cebon, "Performance of a semiactive damper for heavy vehicles," ASME Journal of Dynamic Systems, Measurement and Control, vol. 122, no. 3, pp. 498-506, 2000.

[11] H. Li and R. Goodall, "Linear and non-linear skyhook damping control laws for active railway suspensions," Control Engineering Practice, vol. 7, pp. 843-850, 1999.

[12] W. H. Liao and D. Wang, "Semiactive vibration control of train suspension systems via magnetorheological dampers," Journal of Intelligent Material Systems and Structures, vol. 14, no. 3, pp. 161-172, 2003.

[13] D. Sammier, O. Sename, and L. Dugard, "Skyhook and $\mathscr{H}_{\infty}$ control of active vehicle suspensions: some practical aspects," Vehicle System Dynamics, vol. 39, no. 4, pp. 279-308, april 2003.

[14] S. Savaresi, S. Bittanti, and M. Montiglio, "Identification of semiphysical and black-box models: the case of MR-dampers for vehicles control," Automatica, vol. 41, pp. 113-117, 2005.

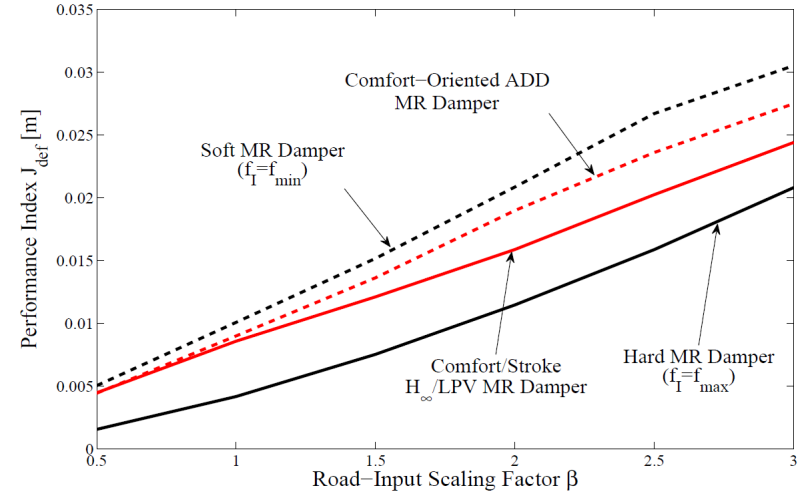

Fig. 12. Performance comparison: Damper deflection

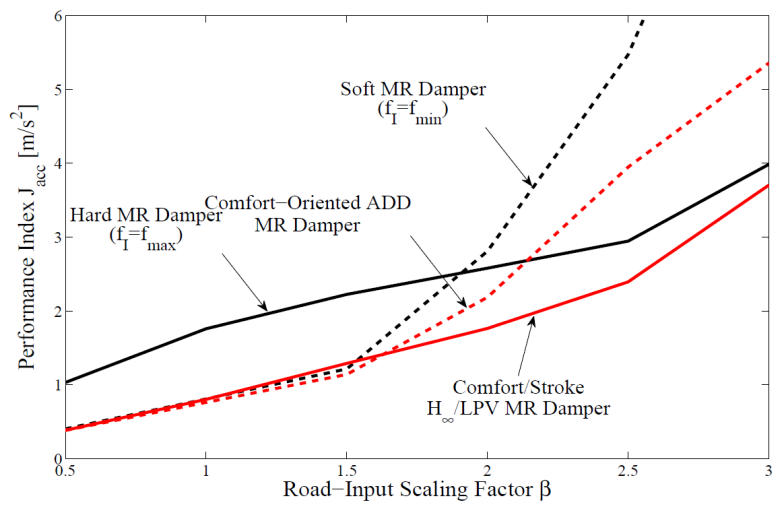

Fig. 13. Performance comparison: Passenger comfort

[15] S. Savaresi and C. Spelta, "A single sensor control strategy for semiactive suspension," to appear in IEEE Transaction on Control System Technology, 2008.

[16] A. L. Do, O. Sename, and L. Dugard, "An lpv control approach for semi-active suspension control with actuator constraints," in Proceedings of the IEEE American Control Conference (ACC), Baltimore, Maryland, USA, June 2010.

[17] S. Guo, S. Yang, and C. Pan, "Dynamic modeling of magnetorheological damper behaviors," Journal of Intelligent Material Systems And Structures, vol. 17, pp. 3-14, January 2006.

[18] L. Zuo and S. A. Nayfeh, " $\mathscr{H}_{2}$ optimal control of disturbance-delayed systems with application to vehicle suspensions," Vehicle System Dynamics, vol. 45:3, pp. 233-247, 2007.

[19] P. Apkarian and P. Gahinet, "A convex characterization of gain scheduled $\mathscr{H}_{\infty}$ controllers," IEEE Transaction on Automatic Control, vol. 40, no. 5, pp. 853-864, may 1995.

[20] C. Scherer, P. Gahinet, and M. Chilali, "Multiobjective outputfeedback control via LMI optimization," IEEE Transaction on Automatic Control, vol. 42, no. 7, pp. 896-911, july 1997.

[21] C. Poussot-Vassal, "Robust multivariable linear parameter varying automotive global chassis control," PhD Thesis (in English), Grenoble INP, GIPSA-lab, Control System dpt., Grenoble, France, September 2008.

[22] A. Zin, O. Sename, M. Basset, L. Dugard, and G. Gissinger, "A nonlinear vehicle bicycle model for suspension and handling control studies," in Proceedings of the IFAC Conference on Advances in Vehicle Control and Safety (AVCS), Genova, Italy, october 2004, pp. 638-643.

[23] A. L. Do, J. Lozoya-Santos, O. Sename, L. Dugard, R. A. RamirezMendoza, and R. Morales-Menendez, "Modélisation et commande lpv d'un amortisseur magnéto-rhéologique," in Proceedings de la Conference Internationale Francophone d'Automatique, Nancy, France, june 2010 